\title{
Server based Mobile Multi-lingual Recognition System of Name-card
}

\author{
Dong-Hyeub Jang ${ }^{\dagger} \cdot$ Jae-Hong Lee ${ }^{+\dagger} \cdot$ Seong-Hak Kim ${ }^{++}$
}

\begin{abstract}
In this study, we developed a server-based mobile multi-lingual name-card recognition system which utilizes smartphone only as a terminal for capturing images of name-card and displaying results of recognition, running server as a recognizer of characters. For efficient processing and transmission of captured images, we corrected the distorted images, removed noises from them, and defined the socket-based protocol for wireless transmission of images between smartphone and the recognizer on server. Various tests for name-cards of five language types show increased recognition rate and speed of the developed system against conventional smartphone-based recognizers.
\end{abstract}

Keywords : Name-card Recognition, Multi-lingual, Smartphone, Mobile

\section{서버기반 모바일 다국어 명함인식 시스템}

\author{
장 동 협 ${ }^{\dagger} \cdot$ 이 재 홍 ${ }^{+\dagger} \cdot$ 김 성 학 ${ }^{+\dagger+}$
}

\section{요 약}

본 연구에서는 문자인식기술의 활용도를 높이고 인식률을 높이기 위해 스마트폰을 문자영상의 입력, 인식결과의 디스플레이, 영상전송을 위한 단말기로만 활용하고 서버에서 문자인식을 처리하도록 하는 서버기반 모바일 다국어 명함인식 시스템을 개발하였다. 인식 시스템에서 는 스마트폰에서 촬영된 영상의 효율적인 처리와 전송을 위해, 왜곡보정과 잡음제거 등을 수행하였고, 인식서버와의 효율적인 영상전송을 위한 소켓기반 프로토콜을 정의하였다. 5 개 언어의 명함들에 대한 다양한 실험을 통해 개발된 시스템이 기존 스마트폰 기반 문자인식기에 비해 향상된 인식률과 인식속도를 보였다.

키워드 : 명함인식, 다국어, 스마트폰, 모바일

\section{1. 서 론}

명함은 흔히 처음 만난 사람에게 자신의 개인정보를 알리 기 위한 수단으로 사용되어 왔으며, 최근에는 인맥관리를 위한 기본 정보로 활용되고 있다. 1990년대 초반부터 문자 인식기술의 상업화가 활발히 시작되었고 휴대용 스캐너와 디지털 카메라 등의 영상입력장치와 IT 기술의 발전에 힘입 어 영상인식 기술은 진화를 거듭하고 있다. 2000년대 들어 활발히 진행되어 온 명함인식 기술은 최근 고해상도 카메라 와 고속 무선통신 기술을 갖춘 스마트폰의 등장과 인맥관리 의 중요성이 대두되면서 모바일 명함인식 앱(App)까지 출시

※ 본 연구는 중소기업청에서 시행한 중소기업기술개발사업의 기술개발 결과임.

† 정 회 원: SMDT 대표

†† 종신회원: 전남도립대학교 보건의료과 교수

ㅎ† 정 회 원 : (주)코아비즈 대표

논문접수: 2013년 11월 4일

수 정 일 : 1 차 2014 년 2 월 12 일

심사완료 : 2014년 3월 28일

* Corresponding Author:Jae-Hong Lee(jhlee@dorip.ac.kr)
되고 있다[1-4]. 기존에 출시되어 시판되고 있는 BizReader, CamCard, WorldCard Mobile은 스마트 폰 앱에 문자인식 엔진 을 탑재하여 인식을 수행하므로 스마트폰의 하드웨어 제약으로 인한 인식 정확도 및 처리시간이 현저히 떨어지는 실정이다.

본 논문에서는 기존 모바일 명함인식 앱이 명함 영상을 획득하여 스마트폰 자체에 장착된 인식엔진을 활용하여 명 함인식을 수행하는 방식에서 벗어나 인식기의 성능개선을 용이하게 할 수 있고 다양한 환경에 쉽게 포팅할 수 있도록 하였으며, 인식엔진만 교체하여 여권, 신분증, 차량번호판 등 으로 문자인식기술의 활용도를 높이기 위해 서버기반 모바 일 명함인식 시스템을 개발하였다. 개발된 시스템에서 스마 트폰은 입력장치(카메라)와 전송수단으로만 활용하고 서버 에 문자인식엔진을 탑재하여 $\mathrm{WiFi}$ 또는 LTE(Long Term Evolution) 방식의 무선인터페이스로 전송받은 명함 영상을 인식하여 그 결과를 스마트폰에 전송하고 있다. 스마트폰에 문자인식엔진을 탑재한 기존 방식은 저성능 프로세서와 저 용량 메모리를 갖춘 스마트폰의 하드웨어 특성상 적정한 인 
식률과 인식속도를 얻을 수 없는 한계를 가지고 있었으나 개발된 시스템은 원격지의 고성능 서버를 활용하여 인식률 과 인식속도를 높일 수 있었다. 본 논문에서는 문자인식 속 도 최적화를 위해 카메라 영상에서 빈번히 발생하는 사다리 꼴 모양의 왜곡을 보정하여 사각형의 반듯한 영상으로 평활 화하고, 촬영된 영상을 무선통신을 통해 서버에 전송할 때 전송량을 줄여 전송속도를 높일 수 있도록 영상크기를 줄일 수 있는 기법을 적용하였다. 또한 스마트폰과 서버 사이의 무선통신을 위한 $\mathrm{TCP} / \mathrm{IP}$ 소켓기반 프로토콜을 정의하였다.

본 논문의 구성은 2장에서 모바일 명함인식 시스템에 대 해 기술하고, 3장에서 구현된 명함시스템에 대하여 다양한 실험 및 평가를 한 후, 4장에서 결론을 맺는다.

\section{2. 모바일 명함인식 시스템}

\section{1 시스템 구성}

시스템의 구성은 Fig. 1과 같이 스마트폰에 탑재되는 클 라이언트 모듈들(전송 클라이언트, 모바일 영상처리, 테스트 용 앱)과 서버에 탑재되는 모듈들(서버용 인식기, 서비스 서 버, 전송서버), 스마트폰과 서버 사이의 전송신호 프로토콜 (SMNP: Smart Mobile Network Protocol)로 구성된다.

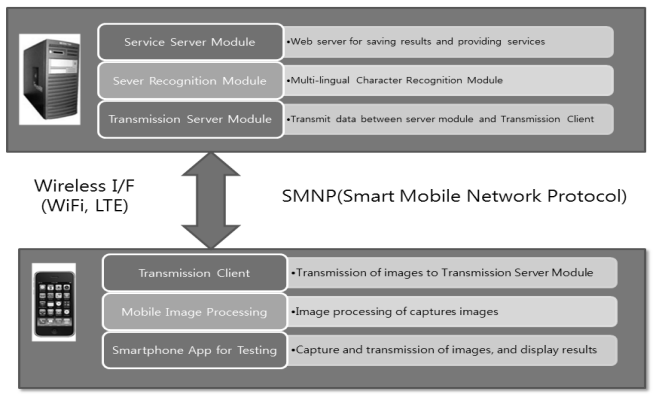

Fig. 1. Block diagram of a server based mobile name-card recognition system

\subsection{SMNP}

$\mathrm{SMNP}$ 프로토콜은 Fig. 2 와 같이 $\mathrm{TCP} / \mathrm{IP}$ 패킷 상에 $\mathrm{HEADER}$ 와 DATA로 구성된다.

\begin{tabular}{c|c|c|c}
\hline \multicolumn{4}{c|}{ SMNP PACKET } \\
\hline \multicolumn{3}{c}{ HEADER (12 Bytes) } & DATA \\
\cline { 1 - 2 } $\begin{array}{c}\text { LENGTH } \\
\text { (4 Bytes) }\end{array}$ & $\begin{array}{c}\text { PACKET_NUMBER } \\
\text { (4 Bytes) }\end{array}$ & $\begin{array}{c}\text { MESSAGE } \\
\text { (4 Bytes })\end{array}$ & $(0 \sim 8192$ Bytes $)$ \\
\hline
\end{tabular}

Fig. 2. Structure of a SMNP packet

Header는 LENGTH, PACKET_NUMBER, MESSAGE로 구성되며, LENGTH는 SMNP PACKET의 총 길이(HEADER+ DATA)를 표시하며, PACKET_NUMBER 필드는 전송되는 패킷의 순서를 표시하며 소켓을 생성하고 서버로 패킷을 전
송하는 순서대로 번호를 부여한다. MESSAGE는 <Table 1> 과 같이 정의된 4 바이트 크기의 정수 값이다. DATA는 전 송방향에 따라 크기 및 구성이 달라지며, PT_REQ_XXXXX 는 클라이언트에서 서버로 정보를 요청할 때 사용되고, PT REP_XXXXX는 서버에서 클라이언트로 보낼 때 사용된다.

Table 1. Messages of SMNP protocol

\begin{tabular}{|c|c|}
\hline MESSAGE & Purpose \\
\hline PT_SVR_READY & $\begin{array}{l}\text { If server setup a socket connection } \\
\text { and is ready to communicate, it } \\
\text { sends this message to client. }\end{array}$ \\
\hline PT_REQ_SVR_CMD & requests a command to a server. \\
\hline PT_REP_SVR_CMD & responses to PT_REQSSVR_CMD message. \\
\hline PT_REQ_SVR_LOGIN & $\begin{array}{l}\text { After connection setup, client registers } \\
\text { its information to a server. }\end{array}$ \\
\hline PT_REP_SVR_LOGIN & $\begin{array}{l}\text { A server sends the result of } \mathrm{PT}_{-} \\
\text {REQ_SVR_LOGIN request to a client. }\end{array}$ \\
\hline PT_REQ_SVR_LOGOUT & $\begin{array}{l}\text { If a client requests LOGOUT to a } \\
\text { server., server deletes LOGIN information } \\
\text { and close a socket. }\end{array}$ \\
\hline PT_REP_SVR_REQUES & $\begin{array}{l}\text { After connection setup, server registers } \\
\text { client's information and sends the } \\
\text { result to the client. }\end{array}$ \\
\hline $\begin{array}{c}\text { PT_REQ_FIND_TARGET } \\
\text { _KIND }\end{array}$ & $\begin{array}{l}\text { search a target client and sends the } \\
\text { result to the client through PT_ } \\
\text { REP_REQUEST. }\end{array}$ \\
\hline PT_REQ_FIND_TARGET & search a target client. \\
\hline PT_REQ_FIND_TARGET & $\begin{array}{l}\text { return the information of a client } \\
\text { which is searched. }\end{array}$ \\
\hline $\begin{array}{l}\text { PT_REQ_BRK_FILE_TR } \\
\text { ANSFER_START }\end{array}$ & $\begin{array}{l}\text { inform the start of file transfer to a } \\
\text { partner. server relays packets to the } \\
\text { target client. }\end{array}$ \\
\hline $\begin{array}{l}\text { PT_REP_BRK_FILE_TR } \\
\text { ANSFER_START }\end{array}$ & $\begin{array}{l}\text { return the result to a partner } \\
\text { requesting file transfer. }\end{array}$ \\
\hline $\begin{array}{c}\text { PT_REQ_BRK_FILE_TR } \\
\text { ANSFER } \\
\end{array}$ & $\begin{array}{l}\text { send files to a partner. server relays } \\
\text { them to the target client. }\end{array}$ \\
\hline $\begin{array}{c}\text { PT_REP_BRK_FILE_TR } \\
\text { ANSFER }\end{array}$ & $\begin{array}{l}\text { return the result of receiving files to } \\
\text { a partner. } \\
\text { server relays them to the target client. }\end{array}$ \\
\hline $\begin{array}{l}\text { PT_REQ_BRK_FILE_TR } \\
\text { ANSFER_CONTROL }\end{array}$ & $\begin{array}{l}\text { sends a file transfer command }(\mathrm{CMD}) \\
\text { to a partner. } \\
\text { CMD: } \\
-1: \text { stop of transfer (at relay server) } \\
0: \text { request of stopping file transfer } \\
\quad \text { (TX↔RX both) } \\
100: \text { transmission is completed } \\
\quad(\mathrm{TX} \rightarrow \mathrm{RX}) \\
200: \text { reception is completed }(\mathrm{RX} \rightarrow \mathrm{TX})\end{array}$ \\
\hline $\begin{array}{l}\text { PT_REP_BRK_FILE_TR } \\
\text { ANSFER_CONTROL }\end{array}$ & $\begin{array}{l}\text { server relays packets to the target } \\
\text { client by using RECV_ID. }\end{array}$ \\
\hline PT_REP_RECOG_PROC & $\begin{array}{l}\text { informs the status of recognizing } \\
\text { the image files which are received } \\
\text { from server. }\end{array}$ \\
\hline PT_REP_RESULT_DATA & $\begin{array}{l}\text { sends the results of recognizing the } \\
\text { requested image files to client. }\end{array}$ \\
\hline
\end{tabular}


스마트폰의 전송클라이언트, 전송서버 모듈과 서버 인식 모듈 사이의 SMNP의 접속절차는 Fig. 3과 같다.

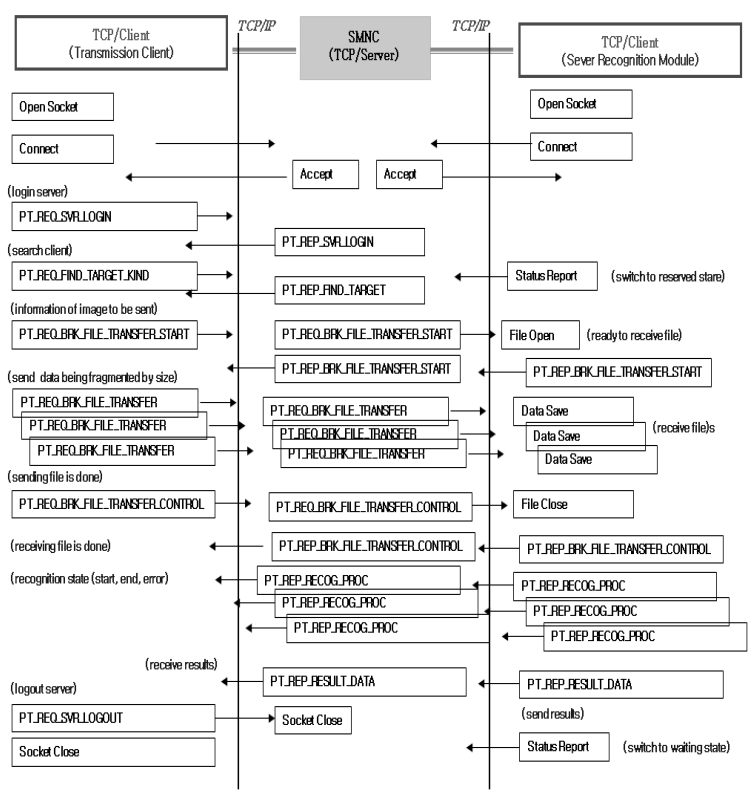

Fig. 3. SMNP connection sequence between smartphone and PC server

\section{3 스마트폰용 모듈}

\subsection{1 모바일 영상처리 모듈}

영상 처리를 서버에서 수행하기 위해 스마트폰에서 명함 영상을 직접 전송하는 경우, 500만 화소 기준으로 촬영된 영상을 JPG로 압축하여 전송할 때 $2.3 \sim 1.9 \mathrm{MB}$ 데이터 트래 픽을 발생시켜 응답시간 지연 및 LTE 접속 환경의 과도한 데이터 사용을 유발시킬 수 있다. 영상 처리모듈에서는 6 단 계(명함 촬영 $\rightarrow$ 명함영상의 경계 추출 $\rightarrow$ 왜곡보정 $\rightarrow$ 잡음 제거 및 영상압축 $\longrightarrow \mathrm{JPG}$ 압축 $\longrightarrow$ 서버로 전송)로 처리하여 $19 \mathrm{MB}$ 의 원영상을 각 단계를 거칠 때마다, $6 \mathrm{MB}, 4 \mathrm{MB}, 2 \mathrm{MB}, 200$ $240 \mathrm{~KB}$ 로 압축하여 전송함으로써 8 10배의 압축률을 얻었다.

모바일 영상처리 모듈은 스마트폰에 장착된 디지털 카메 라를 이용하여 촬영된 명함이거나 기존에 촬영된 영상에 대 해 효율적인 전송 및 인식을 위해 다양한 처리를 수행한다. 500 만 화소 이상의 고해상도 카메라로 촬영된 영상은 인식 대상을 근접촬영(접사)을 하지 않아도 인식에 필요한 최소 화소를 보장할 수 있어 렌즈왜곡 현상은 없다. 그러나 스마 트 폰으로 촬영된 영상은 촬영시의 손 떨림으로 인한 초점 이 일치하지 않고, 스캐너에 비해 광도가 일정하지 않고 난 반사로 인한 명도 값 불일치로 상하-좌우로 기울어져서 사 다리꼴 모양으로 왜곡이 발생한다.

모바일 영상처리 모듈에서는 사다리꼴 모양으로 변형된 영 상에 대한 왜곡보정, 난반사 명도 값 불일치로 인한 잡영 (noise) 제거, 처리속도 최적화를 위한 이미지 압축을 수행한다.

\section{(1) 왜곡보정}

왜곡보정은 사다리꼴 모양으로 촬영된 영상에서 모서리 경계점을 추출하여 사각형 모양으로 반듯하게 평활화(smoothing) 하는 과정이다[5, 6, 7]. 카메라로 촬영된 인식대상은 일반 스캐너로 입력된 영상과 다르게 인식대상과 카메라 각도가 정확하게 $90^{\circ}$ 를 유지할 수 없다, 또한 일반적인 환경에서 수 작업으로 촬영을 하므로 문서의 좌우 기울기도 정확하게 직 각을 유지할 수 없게 된다. 결과적으로 Fig. 4와 같이 비스 듬한 형태의 사다리꼴 모양의 영상을 획득하게 되어서 최종 적으로 인식성능에 영향을 미치게 된다.

사다리꼴 모양 영상의 왜곡보정을 위해 다음 단계들을 거친다.

(1) 원본 영상을 $1 / 16,1 / 65$ 로 축소한다.

(2) 축소된 영상에 대하여 이진화를 수행하여 흑백 영상으 로 변환한다.

(3) 허프변환 알고리즘을 사용하여 경계영역을 추출한다.

(4) 4 개의 모서리 위치를 추출한다.

(5) 추출된 위치정보를 이용하여 보정대상 영역만 추출한다.

(6) 추출된 영상에 대하여 양선형변환(Bilinear Transformation) 알고리즘을 적용하여 반듯하게 보정한다.

왜곡보정 후 사다리꼴 모양의 왜곡된 영상은 Fig. 5와 같 이 보정되었다.

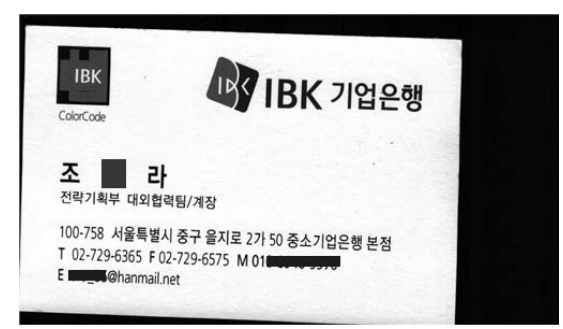

Fig. 4. Trapezoidally distorted image
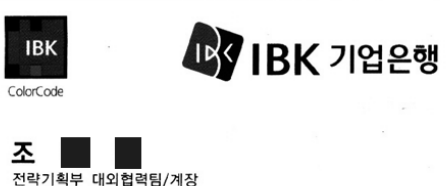

$100-758$ 서울특별시 중구 을지로 2 가 50 중소기업은행 본점 T 02-729-6365 F 02-729.6575 M 01 E ghanmail.net

Fig. 5. Correction of distorted image

(2) 잡영 제거

이진화된 영상에서 연결 성분 분석(Connected Component Analysis) 등을 통하여 영상의 명도 분포를 개선하고 불필 요하게 첨가된 잡영을 제거한다. 이진화된 영상에서 문자 영역 테두리 부분에서 발생하는 테두리 형태의 잡영, 불균 일 명도 분포에 의해 나타나는 고주파수의 Spot 잡영, 조명 반사 등 광량의 변화에 의해 나타나는 잡영을 제거한다. 


\section{(3) 영상압축}

촬영된 영상을 서버로 전송할 때 영상의 크기는 전송속도 에 영향을 미치는 중요한 요소이다. 문자인식엔진이 탑재된 서버로 모든 영상이 전송되어야 하므로 서버의 성능 향상을 위해서도 최적화된 작은 크기의 데이터 변환이 필요하다.

500 만 화소 카메라로 촬영된 RAW 영상은 $19 \mathrm{MByte}(500$ 만 화소×4Byte)의 메모리를 필요로 하며, 이를 JPEG 압축 알고리즘을 사용하여 변환하면 2 19MByte의 크기로 줄일 수 있다. 범용 이미지 압축 알고리즘은 인접화소의 유사한 화소 정보를 대표값으로 변환하거나 빈도가 높은 화소 정보 를 추출하여 대표값으로 변환하여 반복횟수만 기록하는 방 법으로 저장용량을 줄이는 방법을 사용한다. 본 연구에서는 범용 영상압축 방법 이외에 추가적인 기법을 적용하여 최종 영상 크기를 60 120KByte 이내로 줄였다.

(1) 인식대상 영역추출(Crop)에 의한 영상 크기 축소

(2) 인식알고리즘에 최적화된 300dpi 해상도로 변환

(3) 이진화 영상 추출로 인한 칼라 수 조정

(4) 인식에 필요한 특징정보를 추출하여 압축

(4) 최적화된 영상에 대한 JPEG 압축

\subsection{2 전송클라이언트 모듈}

전송클라이언트 모듈은 스마트폰과 서버 내 문자인식모듈 사이의 데이터 전송(중계)를 담당하는 기능을 수행한다. 이 를 위해 $\mathrm{TCP} / \mathrm{IP}$ 소켓 기반의 데이터 송수신을 위해 2.2 에서 정의한 $\mathrm{SMNP}$ 을 사용한다.

\subsection{3 테스트용 스마트폰 앱}

테스트용 스마트폰 앱은 인식대상 명함을 촬영하여 영상 처리를 수행하고 영상을 압축하여 서버로 전송한 후, 인식 결과를 수신하여 화면에 표시하는 기능으로 구성된다. $\mathrm{WiFi}$ 및 $\mathrm{LTE}$ 를 지원하는 아이폰4 이상, 안드로이드 4.0 이상을 지원하는 스마트폰에서 동작한다. Fig. 6에서 Fig. 9는 안드 로이드폰용 테스트 앱에서 명함 영상 선택, 경계선 추출, 인 식대상 언어 선택, 인식결과를 보여주는 화면들이다.

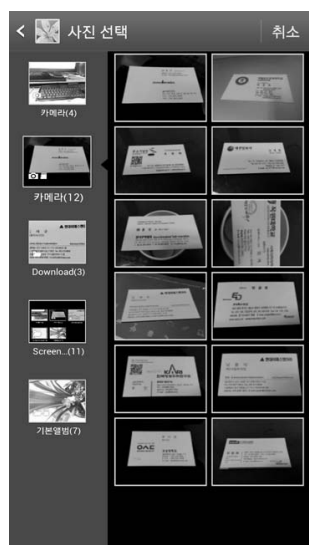

Fig. 6. Image selection view

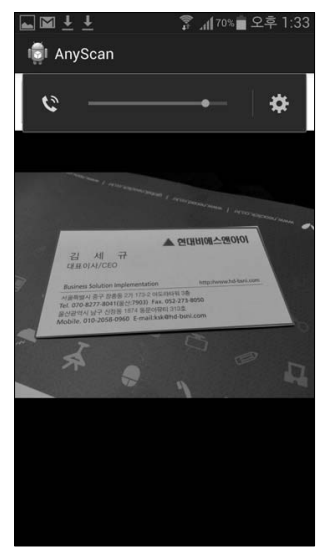

Fig. 7. Boundary extraction view

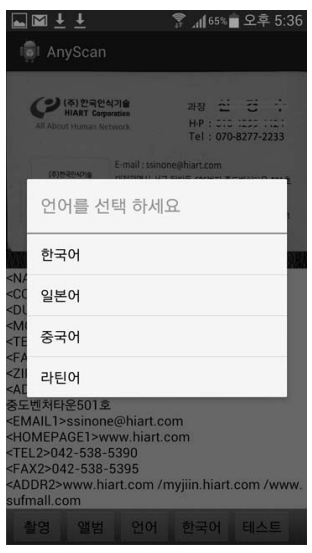

Fig. 8. Language selection menu

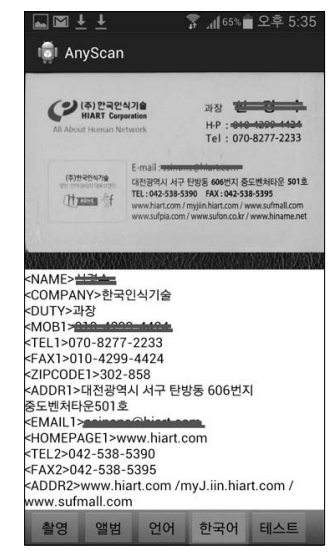

Fig. 9. Recognition results on Smartphone

\section{4 서버 모듈}

\subsection{1 서버 인식모듈}

서버 인식모듈은 스마트폰에서 촬영된 명함영상을 SMNP 프로토콜을 이용하여 무선통신으로 전송받아 줄단위 분리, 개별문자추출, 특징추출 등을 통해 다국어 문자인식을 수행 한다[8, 9]. Fig. 10은 서버 인식모듈에서의 문자인식 과정을 보여준다.

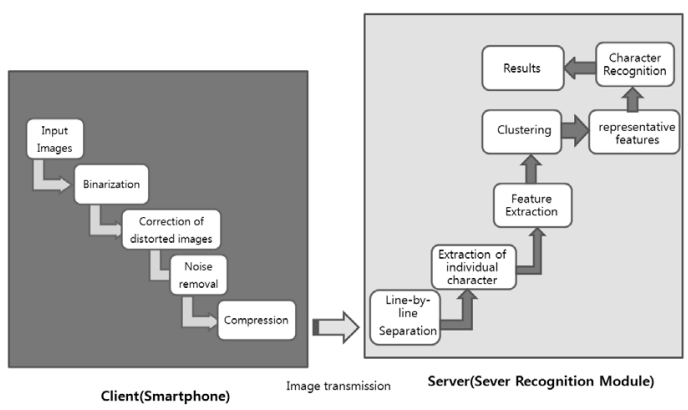

Fig. 10. Character recognition processes in the server recognition module

(1) 줄단위 분리

이진화된 입력영상에서 텍스트 영역을 판단하여 줄 단위 로 구분하는 과정이다[10, 11].

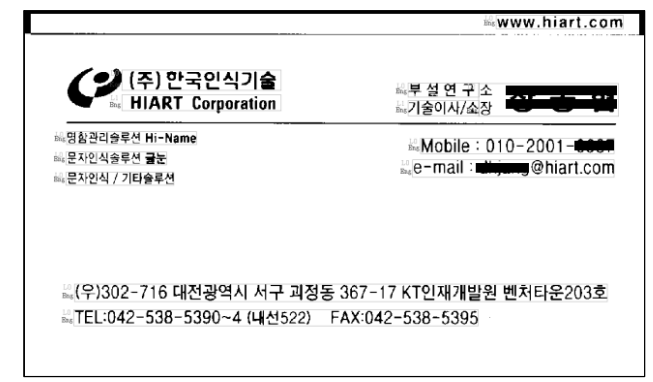

Fig. 11. Line-by-line separation from a binary image 
(2) 개별문자 추출

줄단위로 분리된 영상에서 수평-수직 투영 및 연결 성분 분석을 통해서 개별 문자를 추출한다. 이 단계에서는 상하 및 좌우 테두리 영역 분석과 Object Labeling 기법을 사용했다[10, 11].

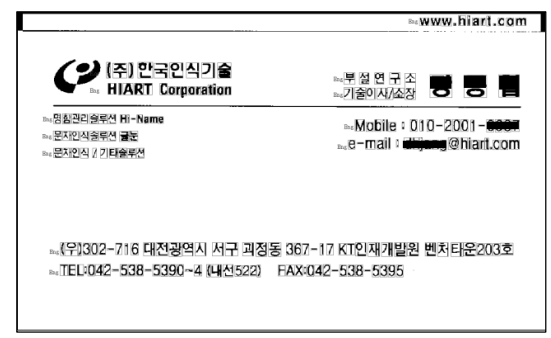

Fig. 12. Extracting individual character images from a line

(3) 특징 추출

추출되어진 문자 영역 정보를 기반으로 효과적인 인식을 위해서는 영역의 크기와 무관한 특징 추출이 요구된다. 이 를 위해 영상정보의 손실을 최소화하면서 패턴들 사이의 충 분한 비교 특징을 가질 수 있도록 보간법을 사용하여 일정한 크기로 영상을 재구성하는 정규화가 수행된다. 추출된 영상 을 $32 \times 32$ 의 크기로 정규화한 후, 전역적 - 구조적·통계적 특 징 등을 활용하여 개별문자에 대한 특징들을 추출한다.

(4) 학습 및 인식

인식과정에서 수행되는 정합과정에 필요한 대표 표본 특징 들을 구하기 위해서 인식 과정 전에 학습과정이 수행된다. 이 를 위하여 다양한 클러스터링(Clustering) 알고리즘이 적용 되었다[12, 13]. 서버인식모듈은 역전파(backpropagation) 학 습 알고리즘을 이용한 다층 퍼셉트론(multi-layer perceptron) 을 이용하였으며[9], 인식률을 향상시키기 위해 직위, 우편번호, 주소 등의 명함에 사용되는 정보를 활용한 후처리를 하였다.

\section{4 .2 서버 전송모듈}

스마트폰의 전송클라이언트와 서버 전송모듈은 비동기 $\mathrm{I} / \mathrm{O}$ 방식으로 2.2 절에서 기술한 $\mathrm{SMNP}$ 프로토콜을 이용하여

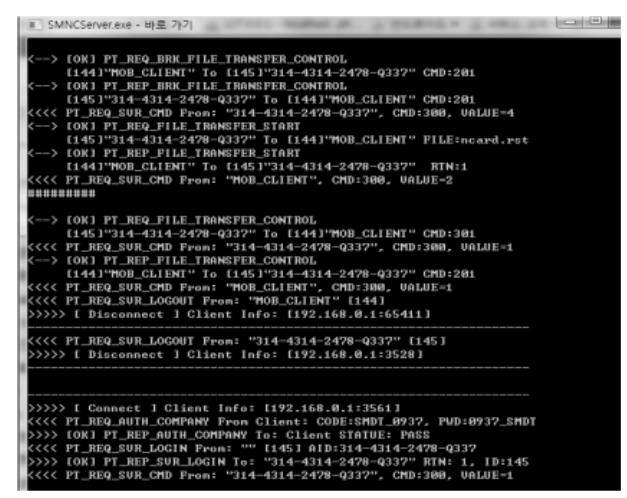

Fig. 13. Connection setup between a transmission client and a server transmission module.
스마트폰에서 획득한 영상 및 서버의 문자인식결과를 전송 한다. Fig. 13은 SMNP을 이용한 서버 전송모듈과 전송클라 이언트와의 접속절차를 보여준다.

\section{3. 실험 및 고찰}

본 연구에서 개발된 서버 기반 모바일 명함인식시스템의 성능을 시험하기 위해 <Table $2>$ 의 하드웨어 환경에서 다 양한 실험을 수행하였다.

Table 2. System specifications for testing

\begin{tabular}{|c|c|c|c|c|c|}
\hline \multicolumn{3}{|c|}{$\mathrm{PC}$} & \multicolumn{3}{|c|}{ Smartphone } \\
\hline & Sever & $\begin{array}{c}\text { Transmission } \\
\text { Client }\end{array}$ & & iPhone5 & $\begin{array}{c}\text { Galaxy S3 } \\
\text { LTE }\end{array}$ \\
\hline CPU & $\begin{array}{l}\text { Intel i5 } \\
3.2 \mathrm{GHz}\end{array}$ & $\begin{array}{l}\text { Intel i3 } \\
3.4 \mathrm{GHz}\end{array}$ & $\mathrm{AP}$ & $\begin{array}{c}\text { Dual } \\
\text { core A6 }\end{array}$ & $\begin{array}{c}\text { Quad core } \\
\text { Snapdragon } \\
800\end{array}$ \\
\hline Memory & $8 \mathrm{~GB}$ & $4 \mathrm{~GB}$ & Memory & $2 \mathrm{~GB}$ & $2 \mathrm{~GB}$ \\
\hline OS & $\begin{array}{c}\text { Windows Sever } \\
2008 \text { R2 }\end{array}$ & $\begin{array}{c}\text { Windows } 7 \\
\text { 64Bit }\end{array}$ & OS & iOS6 & Android 4.3 \\
\hline $\begin{array}{l}\text { Graphic } \\
\text { Card }\end{array}$ & $\begin{array}{c}\text { GTX650 T1 } \\
1 \mathrm{~GB}\end{array}$ & $\begin{array}{c}\text { Intel HD } \\
4000\end{array}$ & $\begin{array}{c}\text { Camera } \\
\text { Resolution }\end{array}$ & $800 \mathrm{M}$ & $1300 \mathrm{M}$ \\
\hline \multirow{2}{*}{$\begin{array}{l}\text { Main } \\
\text { Board }\end{array}$} & \multirow{2}{*}{$\begin{array}{c}\text { Gigabyte } \\
\text { H81M-D3 }\end{array}$} & \multirow{2}{*}{$\begin{array}{c}\text { Gigabyte } \\
\text { H61M-DS2 }\end{array}$} & Storage & $16 \mathrm{~GB}$ & $16 \mathrm{~GB}$ \\
\hline & & & Display & $\begin{array}{l}\text { LCD 4" } \\
326 \mathrm{ppi}\end{array}$ & $\begin{array}{c}\text { LCD 5.7" } \\
388 \mathrm{ppi}\end{array}$ \\
\hline
\end{tabular}

스마트폰에서 촬영된 명함영상에 대해 왜곡보정, 잡음제 거, 효율적인 압축 등의 영상처리를 거친 후 서버로 전송하 여 영상파일로 저장하는 데 소요되는 영상전송시간, 서버가 인식결과 전송을 시작하여 스마트폰에서 결과화면이 표시되 기까지 걸린 인식결과 수신시간, 사다리꼴 모양의 명함영상 에 대한 왜곡보정률, 인식성능(인식시간과 인식률) 등에 대 해 언어 당 200개의 다양한 명함들을 대상으로 실험하였다.

\section{1 개발된 서버기반 인식시스템의 성능평가}

\section{1 .1 영상 전송시간}

스마트폰의 시작버튼을 누르고, 서버에서 영상파일로 저 장할 때까지 걸린 시간을 측정하였다. 200장의 명함에 대해 실험한 결과 미전송 오류는 발생하지 않았으며, $\mathrm{WiFi}$ 환경 에서 평균 $207 \mathrm{~ms}, \mathrm{LTE}$ 환경에서 평균 $213 \mathrm{~ms}$ 의 전송속도를 보였다.

\section{1 .2 인식결과 수신시간}

서버가 인식결과 전송을 시작하여 스마트폰에 결과화면이 표시되기까지 걸린 시간을 측정하였다. 200장의 명함 시험 결과 $\mathrm{WiFi}$ 환경에서 평균 $174 \mathrm{~ms}, \mathrm{LTE}$ 환경에서 평균 $180 \mathrm{~ms}$ 의 전송속도를 보였다. Fig. 14는 실험에 사용된 명함들의 예와 $\mathrm{WiFi}$ 와 $\mathrm{LTE}$ 환경에서의 영상전송시간 및 인식결과 수신시간을 보여준다. 


\begin{tabular}{|c|c|c|c|}
\hline \multirow{5}{*}{ 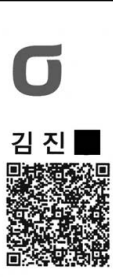 } & \multirow{4}{*}{ 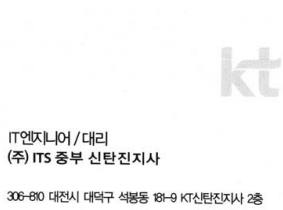 } & Category & Value \\
\hline & & Image Size & $48 \mathrm{~KB}$ \\
\hline & & WiFi Tx time & $195 \mathrm{~ms}$ \\
\hline & & LTE Tx time & $198 \mathrm{~ms}$ \\
\hline & $\begin{array}{l}\text { To 042-935-2041 } \\
\text { F 042-910-2858-1899 }\end{array}$ & Avg. Tx time & $196.5 \mathrm{~ms}$ \\
\hline
\end{tabular}

(A) Transfer time of the processed image of a name-card to server

\begin{tabular}{|c|c|c|c|}
\hline \multirow{3}{*}{ 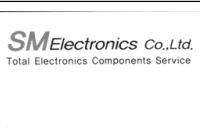 } & \multirow{5}{*}{ 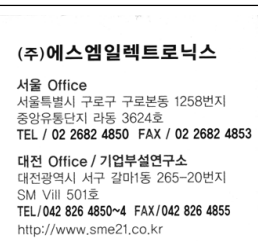 } & Category & Value \\
\hline & & Image Size & $81 \mathrm{~KB}$ \\
\hline & & WiFi Tx time & $181 \mathrm{~ms}$ \\
\hline \multirow{2}{*}{$\begin{array}{l}\text { 부설연구소 / 소장 } \\
\text { 동 } \\
\text { Mobile : } 010 \text { 9414 } \\
\text { E-mal : }\end{array}$} & & LTE Tx time & $186 \mathrm{~ms}$ \\
\hline & & Avg. Tx time & $183 \mathrm{~ms}$ \\
\hline
\end{tabular}

(B) Receiving time of recognition results from server

Fig. 14. Examples of name-cards for testing

\section{1 .3 영상왜곡보정}

200장의 명함을 대상으로 실험한 결과 195장의 명함을 정 상 왜곡보정 처리했다. 다만, 조명, 명함의 테두리 색상, 두 가지 이상의 배경색 명함에 따라 5 장의 명함이 경계추출 오 류를 발생했다.

\section{1 .4 인식성능}

한국어, 중국어, 일본어, 영어, 라틴계의 5 개 언어로 된 명 함에 대하여 서버의 인식률을 평가하였다. 인식률은 (정인식 글자수)/(전체 글자수) $\times 100$ 으로 계산하여 퍼센트(\%)로 측 정하였다. Fig. 15는 실험에 사용된 5 개 언어 명함들에 대한 영상과 인식결과를 보여준다.

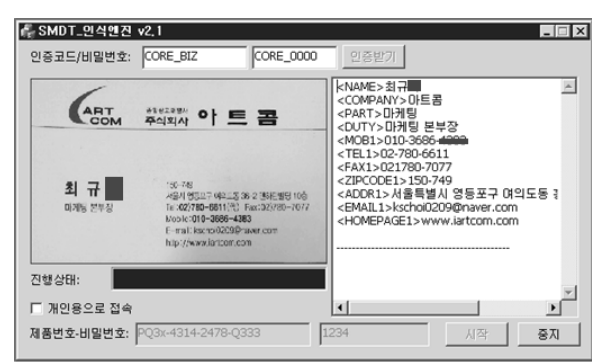

(A) Korean name-card

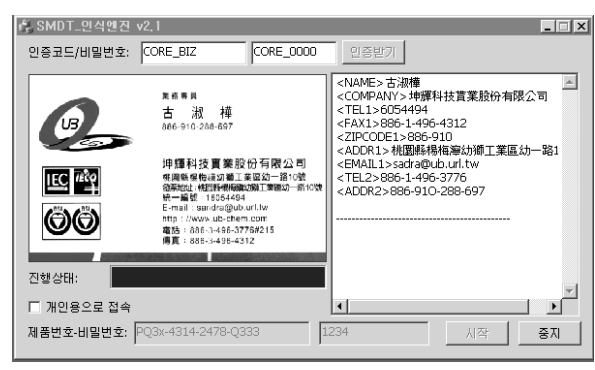

(B) Chinese name-card
언어별 200장 명함의 인식성능을 측정한 결과 <Table 3>과 같이 언어별 91 99\%의 인식률을 보였으며, 인식처리 속도 는 평균 700 1200ms가 소요되었다. 명함의 필드 수, 글자 수 에 따라 처리시간이 가변적이었고, 영어 명함의 처리속도가 다른 언어에 비해 빠른 처리속도를 나타냈다. 명함인식에 사 용된 필드 개수는 8 개로 이름, 상호, 직위, 휴대폰, 팩스, 전화 번호, 이메일, 주소이다.

Table 3. Recognition rates of multi-lingual name-cards

\begin{tabular}{c|c|c|c|c}
\hline Language & $\begin{array}{c}\text { Total } \\
\text { characters }\end{array}$ & Correct & Incorrect & $\begin{array}{c}\text { Average } \\
\text { recognition } \\
\text { rate(\%) }\end{array}$ \\
\hline Korean & 20,113 & 19,530 & 583 & 97.0 \\
\hline Chinese & 19,318 & 17,679 & 1,639 & 91.5 \\
\hline Japanese & 19,975 & 18,617 & 1,358 & 93.2 \\
\hline English & 22,078 & 21,897 & 181 & 99.1 \\
\hline Latin & 21,510 & 21,324 & 186 & 99.1 \\
\hline
\end{tabular}

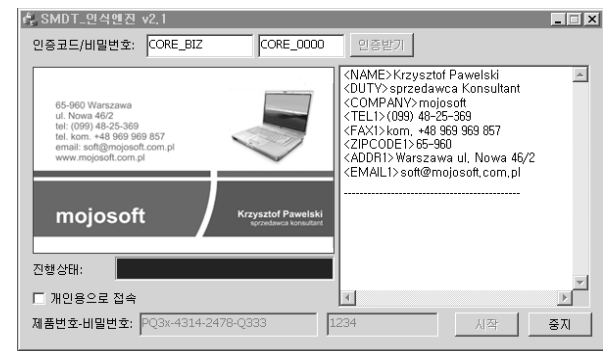

(C) Latin language name-card

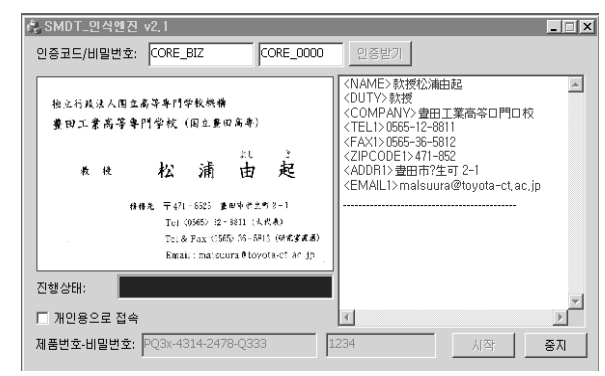

(D) Japanese name-card

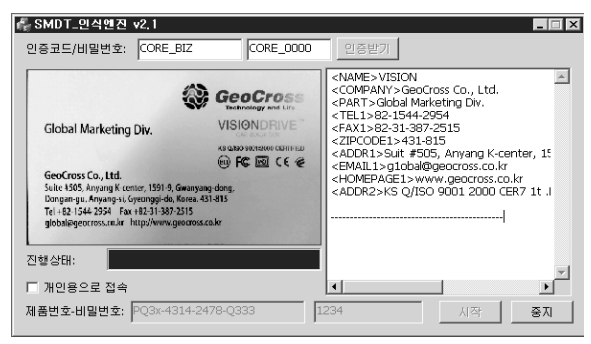

(E) English name-card

Fig. 15. Samples of recognition results for multi-lingual name-cards 


\section{1 .5 총 처리시간}

모바일 명함인식시스템 $($ 영상 촬영 $\rightarrow$ 영상처리 $\rightarrow$ 전송 $\rightarrow$ 인식 $\rightarrow$ 결과수신)의 총 처리시간을 평가하기 위해 스마트폰에서 명 함을 촬영하여 전송 버튼을 누른 후 인식결과 화면이 표시 되기까지 소요된 시간을 측정하였다. 200장의 명함 실험 결 과 $\mathrm{WiFi}$ 환경에서 평균 $1,081 \mathrm{~ms}, \mathrm{LTE}$ 환경에서 평균 1,593 $\mathrm{ms}$ 의 처리시간이 소요되었다.

\section{2 기존 연구와의 비교}

상용 스마트폰 기반 명함인식 앱인 CamCard[14]와의 인 식률과 인식속도를 비교했을 때, CamCard는 영어에서 $98 \%$ 이상의 인식률을 보이고 있으나 한글에서는 다소 낮은 인식 률을 보였다. 스마트폰 자체에 인식엔진을 탑재하다 보니 명함 고유의 특성(직책, 주소 등)을 반영하기 위한 후처리 기술이 미약한 것으로 보이며, 외국산이다 보니 한글주소와 회사명 등의 처리에 오류가 많았다. CamCard의 인식속도는 약 2 3초 이내이며, 개발된 서버기반 시스템은 $1 \sim 1.5$ 초로 전송 트래픽으로 인한 속도 지연(약 207 213ms)은 있으나 이는 인식속도에 지장을 주지 않고 있다. 본 연구에서 개발 된 시스템에서 서버의 문자인식모듈을 스마트폰에 포팅하여 200장의 한글명함만을 대상으로 인식한 결과, 인식률은 $93.8 \%$ 를 보여 서버기반에 비해 약 $3.2 \%$ 의 차이를 보였으며, 하드웨 어 제약으로 다양한 언어 및 후처리를 지원할 수 없었다.

\section{4. 결 론}

본 연구에서는 기존 스마트폰 자체에서 명함인식을 수행 하는 방식에서 탈피하여 스마트폰은 명함을 촬영하여 문자 인식엔진이 탑재된 고성능 서버로 전송하여 인식결과를 도 시하는 단말기로만 활용하는 서버기반 모바일 명함인식 시 스템을 개발하였다. 스마트폰에서 문자인식을 수행하는 경 우 하드웨어 제약으로 다양한 언어를 지원하기 어렵고 인식 속도와 인식률도 만족스럽지 못했다. 서버 기반 모바일 명 함인식 시스템을 위해 영상 데이터 크기를 줄이고 우수한 인식률을 얻기 위해 스마트폰 카메라로 촬영된 영상에 대해 왜곡보정, 잡음제거, 효율적인 압축 등의 영상처리를 수행하 였으며, 서버로 영상을 전송하기 위한 통신프로토콜을 정의 하였다. 개발 시스템의 성능을 측정하기 위해 5 개 언어에 대해 아이폰과 안드로이드폰용 앱을 개발하여 언어별 200 개 의 명함을 대상으로 인식속도, 인식률, 시스템 처리시간 등 의 다양한 실험을 수행하였다. 명함인식시스템의 성능향상 을 위해서는 향후 조명 및 난반사에 대한 영상처리 기법에 대한 연구가 진행되어야 할 것이다. 개발된 시스템은 신분 증 인식 등의 문자인식 분야와 인맥관리 서비스 분야에 활 용될 수 있으며, 인식대상을 확대하고 번역시스템과 연동하 여 다양한 언어로 표기된 광고판, 관광안내문 등의 번역 및 관광 서비스 분야에 적극 활용될 수 있을 것이다.

\section{Reference}

[1] "Recognition, storage method of name-card, and system using name-card management server", Korea Patent pending, 10-2013-0026601, 2013.

[2] "Apparatus and method for photographing a business card in portable terminal", Korea Patent 10-0784332, 2007.

[3] "Name-card management system using mobile terminal", Korea Patent 10-1277669, 2013.

[4] "Computer remote name-card management device and method using mobile terminal", Korea Patent pending, 10-2011-0107622, 2011.

[5] D. G. Jang and E. J. Kim, "Character Shape Distortion Correction of Camera Acquired Document Images", The Journal of The Korean Institute of Maritime Information \& Communication Sciences, Vol.10, No.4, pp.680-686, 2006.

[6] W. P. Yu and Y. K Chung, "An Image Warping Method for Implementation of an Embedded Lens Distortion Correction Algorithm”, The KIPS Transactions: Part B, Vol.10, No.4, pp.373-380, 2003.

[7] K. K. Kim and J. H. Kim, "Local Adaptive Binarization Algorithm of Document Image Captured by Mobile Phone Camera”, Journal of KSIST, Vol.10, No.1, pp.17-26, 2004.

[8] J. D. Kim, "A Study on the Character Recognition Algorithm in order to Recognize Printed Mixed Documents", Master dissertation, Hanyang Univ., 2009.

[9] D. H. Jang and J. H. Lee, "A Development of Unicode-based Multi-lingual Namecard Recognizer", The KIPS Transactions: Part B, Vol.16, No.2, pp.117-122, 2009.

[10] K. H. Kim. I. D. Lee, O. S. Kwon and T. K. Kim, "A study on the preprocessing system of document for Korean document”, in Proc. of KISS Spring, Vol.17, No.1, 1990.

[11] I. D. Lee, "A method to extract characters and non-characters seperately from document image", Journal of KIISE, Vol.17, No.3, pp.247-258, 1990.

[12] Tapas Kanung, "The Analysis of a Simple k-Means Clustering Algorithm," in Proc. of ACM Symposium on Computational Geometry, June, 2000.

[13] S. W. Lee, H. J. Oh, D. U. An and S. J. Jeong, "An Implementation of K-Means Algorithm Improving Cluster Centroids Decision Methodologies", The KIPS Transactions: Part B, Vol.11, No.7, pp.867-874, 2004.

[14] INTSIG Information Co. Ltd, "CamCard", http://www.camcard.com 


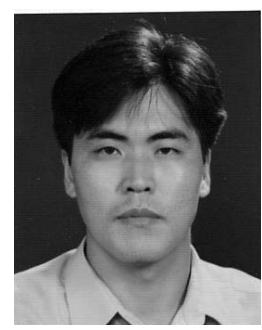

\section{장 동 협}

e-mail : dhjang2002@gmail.com

1994년 한밭대학교 전자계산학과(학사)

1996년 한밭대학교 전자계산과(공학석사)

1998년 2002년 (주)아론통신기술

2002년 2012년 (주)한국인식기술 부설

$$
\text { 연구소 소장 }
$$

2013년 현 재 SMDT 대표

관심분야: 문자인식, 음성인식, $\mathrm{HCI}$, 네트워크 망관리 등

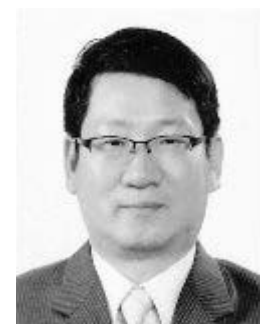

\section{이 재 홍}

e-mail : jhlee@dorip.ac.kr

1999년 충남대학교 컴퓨터공학과(공학박사)

1988년 1994년 국방과학연구소 연구원

1994년 1995년, 1999년 (주)한국인식기술 연구원

2000년 현 재 전남도립대학교 보건의료 과 교수

관심분야: 문자인식, 멀티미디어, 임베디드 시스템

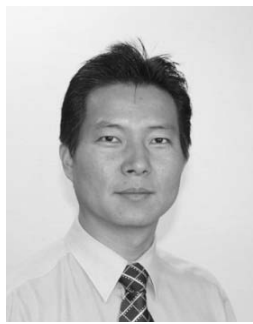

\section{김 성 학}

e-mail :mail@corebiz.co.kr 1995년 서원대학교 경영학과(학사) 2007년 충남대학교 Project관리학과 (이학석사)

1996년 2005년 (주)한국인식기술 부설 연구소 부장

2006년 현 재 (주)코아비즈 대표 관심분야: 문자인식, 영상처리, 번역 및 음성인식, 패턴인식 